\title{
VIOLÊNCIA SIMBÓLICA NO TRABALHO: CONSIDERAÇÕES EXPLORATÓRIAS SOBRE A NOVA ONTOLOGIA DO TRABALHADOR NA PÓS-MODERNIDADE
}

\author{
Cristina Myuki Hashizume ${ }^{1}$
}

\section{RESUMO}

Apesar de já termos superado modelos de trabalho que desconsideravam a inteligência do funcionário, encarando-o como máquina, como os modelos Taylorista e Fordista, e termos ingressado numa nova ordem de relações organizacionais mais horizontalizadas que valorizam a participação e a criatividade do funcionário (Toyotismo), ainda é notável a exploração desigual da empresa em relação ao funcionário em nome da ética do capital. O mundo pós moderno rompe com paradigmas e parâmetros estáveis da organização do mundo moderno, inserindo valores como o risco, a flexibilidade, a ilegibilidade, deixando o trabalhador à deriva da possibilidade de planejar sua carreira profissional a médio ou longo prazo. Com isso, deparamo-nos com um trabalhador que tem a sua rotina e valores (caráter) desvirtuados por uma lógica que prioriza a subserviência às mudanças instantâneas do mercado. Sennet (2000) propõe um entendimento de que o caráter do trabalhador pós moderno está corroído, tamanha é a instabilidade e a dificuldade de se manter os laços e compromissos entre trabalhadores e destes com a chefia. Frente a esse cenário, surge um novo paradigma, que elegemos como nosso tema no presente artigo, que instiga os trabalhadores e grandes empresários a cultuar a sua auto performance (EHRENBERG, 2010). A figura do workaholic, outrora vista como uma patologia, hoje é considerada o ideal de dedicação no trabalho. O mundo do trabalho pós-moderno assimila o discurso do competidor esportista: por se tratar de um jogo, ainda que as metas não tenham sido alcançadas naquela ocasião, há novas oportunidades de se recuperá-la, em outras partidas. Dessa forma, controla-se o sujeito de forma onipresente, como já havia teorizado Delleuze (1992), em sua sociedade do controle. No presente trabalho iremos focar a violência simbólica cometida pelas corporações em relação a seus funcionários. Nosso objetivo é demonstrar teoricamente que tal violência se trata de uma prática institucionalizada e que está dentro de uma lógica de mercado que impera nas grandes corporações. Partindo do histórico das práticas de controle e biopoder, traremos a discussão sobre o assédio moral, expressão em alta, que preferimos chamar de violência simbólica. O termo assédio está em voga, foco de inúmeras publicações especializadas. O uso desse novo termo, porém, não rompe com a lógica já existente entre vítimas e algozes, nem problematiza questões para além de uma função pragmática e alienada de mundo. Concluímos que frente à nova ontologia do trabalhador, a violência simbólica ocorre de modo consentido pelo trabalhador. A violência institucionalizada deve ser contextualizada a partir da compreensão das novas relações de trabalho, ambientadas num capitalismo financeiro que vê em tudo um fim lucrativo e performático. O conceito de assédio acompanha o processo de juridicialização do direito social, que intenta tornar mais justa as relações sociais, seguindo, porém, um princípio equivocado: coloca no indivíduo o poder de julgar a tudo e a todos, restabelecendo a justiça de forma privatista.

Palavras-chave: Assédio moral. Violência Simbólica no Trabalho. Subjetividade Capitalística. Ética.

${ }^{1}$ Doutora. Docente Psicologia do Trabalho e Organizacional da Universidade Estadual da Paraíba (UEPB). E-mail: crismiyu @gmail.com. 


\section{ABSTRACT}

Although we have already overcome working models which disregarded the worker intelligence, viewing him as a machine, as the Taylorist and Fordist models, and that we entered in a new order of more flatter organizational relationships that value the participation and creativity of the employee, it is still remarkable uneven exploration of the company in relation to the employee on behalf of the ethics of capital. The postmodern world breaks paradigms and stable parameters of the organization of the modern world, entering values like risk, flexibility, illegibility, leaving the worker adrift of the possibility of planning his career in the medium or long term. With this, we are faced with an employee who has his routine and values (character) distorted by a logic that prioritizes instant subservience to market changes. Sennet (2000) proposes that an understanding of the character of the postmodern worker is eroded, such is the instability and the difficulty of maintaining ties and commitments between workers and those with leadership. Faced with this scenario, there is a new paradigm that we elect as our theme in this article, which instigates the workers and business leaders to worship their self-performance (Ehrenberg 2010). The figure of workaholic, once seen as pathology, today is considered the ideal of dedication at work. The modern world of post workflows assimilates speech competitive sportsman, because it is a game, even though the goals have not been achieved on this occasion, there are new opportunities to get it in other games. Thus, control is the subject of ubiquitous way, as Delleuze (1992) had theorized, in his Company's Control. In this paper we focus on the symbolic violence committed by corporations in relation to their employees. Our goal is to demonstrate theoretically that such violence is an institutionalized practice and that it is within a market logic that prevails in large corporations. Starting from the historical practices of control and biopower, we will bring the discussion about moral siege, for high expression, we prefer to call symbolic violence. The term siege is in evidence, the focus of specialized publications. The use of this new term, however, does not break with the logic that exists between victims and executioners, nor does it discuss issues beyond a pragmatic function and alienated world. We conclude that facing the new ontology of the worker, the symbolic violence occurs in a consent form by the worker. Violence as institutionalized must be contextualized from the understanding of new working relationships, acclimated to a financial capitalism that sees everything in a lucrative and performativity order. The concept of siege follows the legal process of social right, which tries to make social relations fairer, however, following a mistaken principle: places on the individual the power to judge everything and everyone, restoring justice privately.

Keywords: Moral Siege. Symbolic Violence at Work. Capitalistic Subjectivity. Ethics. 


\section{Introdução}

O presente trabalho problematiza a violência simbólica nas empresas e no mundo do trabalho. Definimos violência simbólica como ação ou omissão destinada a degradar ou controlar os comportamentos, os modos de pensar e as decisões de outra pessoa. Utilizamos o termoviolência simbólica a esse fenômeno pelo fato de que, diferente dos termos bullying ou assédio moral, ou mesmo mobbing, que são contextualizados em análises que privatizam as relações de justiça e igualdade social, estamos conceituando um processo que está atrelado a um contexto maior, global, ao qual estamos em conectividade. A opção por essa terminologia, portanto, passa por um referencial éticopolítico, no sentido de que nos provoca a problematizar não apenas aquele que comete a violência e sua vítima, mas sim, os modos de subjetividade que vêm sendo produzidos: ora a partir da flexibilidade do mercado, ora das diretrizes organizacionais bem focadas, que vão de encontro com a humanização nas relações no trabalho e o respeito pela diversidade dos trabalhadores. Também diferenciamos a violência simbólica da chamada violência psicológica, por acreditarmos que as decorrências daquele fenômeno não se repercutem apenas no plano psicológico (no sentido estrito de que ocasionaria patologias ou sequelas psicológicas, que um tratamento especializado as sanaria, fazendo o indivíduo voltar à normalidade).

Primeiramente discutiremos a sociedade disciplinar, a sociedade do controle, o conceito de assédio moral, demarcando um contexto sóciopolítico-econômico que aponta a privatização do público, ou, nas palavras de Sennett (2001), o declínio do homem público. A violência simbólica, portanto, vem de longa data, configurando-se de formas específicas em cada momento histórico. Por fim, concluímos com a discussão de que o termo assédio não passa de uma nova terminologia que não problematiza questões fundamentais para colocarmos em questão as relações sociais e de trabalho na contemporaneidade. Concluímos questionando a nova ontologia do trabalhador na pósmodernidade, requerida pelas grandes corporações em todo o planeta, de modo a tornar institucionalizada a violência no trabalho. Atingindo a moral do trabalhador através de diretrizes invasivas, objetivamente focada no capitalismo financeiro, tal ética transforma o trabalhador em mero produtor de lucratividade para as empresas, reificando o sujeito e o trabalho e empobrecendo a possibilidade de exercício de um labor criativo e transformador. 
A relevância desse trabalho é seu engajamento num dos objetivos propostos neste artigo: o de justamente articular duas temáticas opostas de estudos sobre a justiça: a que lida com o crime, as organizações populares e os pobres e aquela que aborda as instituições, a política e as elites. A discussão da violência simbólica, em nível institucional/organizacional demonstra que mesmo instituições que fazem parte de um grupo seleto de pessoas mais esclarecidas, cultas e elitizadas, podem cometer injustiças no âmbito psicológico, simbólico ou moral. E isso decorre do fato de que não se trata de desconhecimento de direitos trabalhistas ou falta de escolarização dos gestores dessas corporações. Trata-se do seguimento de uma ética das grandes corporações, que financeiriza o valor do trabalhador a partir de sua produtividade quantitativa e capacidade de alcance às metas impostas.

\section{Sobre a violência}

Trata-se de um assunto do momento, muito se fala de bullying, mobing, violência simbólica, violência psicológica e de assédio moral. Da mesma forma como há tantas terminologias para designar essa intolerância para com o diferente, também há uma grande diversidade de referenciais teóricos que trabalham com o tema. É importante saber diferenciá-los, pois esses termos têm sido usados com intuitos diferentes, baseados em referenciais diferentes ou abordam a situação a partir de contextos e situações peculiares, o que nos impede de compará-los pari passu.

Um questionamento epistemológico se faz necessário: em que medida tantos conceitos diferentes de violência simbólica, um fenômeno tão antigo, possibilitariam, de fato, a compreensão do fenômeno da violência no trabalho? De que maneira poderíamos ir além do levantamento de causas e consequências desse fenômeno que envolve relações interpessoais e intersubjetivas no trabalho? Tal definição inovadora nos permite ir contra uma ciência instrumentalizada a serviço da manutenção da ordem social desigual? Nesse sentido, devemos refletir se a adoção de uma tipologia e classificação dos tipos de assédio moral ou violência simbólica não mascaram os processos inerentes ao surgimento desse fenômeno e mesmo que o reconheçam, correndo o risco de tratá-lo como um fenômeno natural. 
Devemos recuperar a necessidade de a ciência contribuir ética e politicamente com o desenvolvimento da humanidade e não para a adaptação dos indivíduos a uma ordem social desigual como a que presenciamos. Temos o desafio ético-político de articular duas perspectivas diferentes: reconhecer as influências sociais exteriores ao homem e recuperar a influência dos processos psicológicos na formação da subjetividade da sociedade pós moderna, sem que essa compreensão contribua com a adaptação e massificação do sujeito.

A discussão sobre assédio moral está na veia do paradigma pós moderno no mundo do trabalho: a crise nos valores morais e nas instituições sociais, aliada ao tratamento do ser humano como um "recurso" da empresa faz com que a solidariedade, lealdade e outros valores humanos sejam relegados a segundo plano, senão desconsiderados. Soma-se a isso um discurso do gerenciamento, que ratifica a valorização do progresso e do desenvolvimento infinitos, exigindo do trabalhador "desempenho" e submissão à "satisfação das necessidades" dos clientes, necessidades essas, que são forjadas dentro de um referencial consumista.

Em nosso trabalho, o objetivo é problematizar a violência simbólica, redefinindo o conceito de assédio moral como prática institucionalizada e muito mais comum do que a bibliografia jurídica e psicológica nos apresentam. Acreditar que algumas organizações empresariais praticam assédio ou violência institucionalizados por serem excepcionalmente antiéticas ou infringirem as leis trabalhistas, para nós, não faz sentido. $\mathrm{O}$ que defendemos pode ser interpretado pelo fato de estarem inseridas num contexto organizacional que requer uma postura organizacional mais agressiva, competitiva e intolerante com a baixa produtividade do trabalhador (EHRENBERG, 2010). Nesse cenário, em nosso entendimento, há quase que institucionalizada uma postura organizacional, alinhada a preceitos que transformam a antes chamada submissão a uma ordem, ao engajamento no projeto da empresa. Através de um fenômeno que Pagès (2005) chama de "domínio ideológico", a missão da empresa é assimilada de modo consentido pelo trabalhador, que acredita se autocontrolar (autoviolentar) devido a sua própria vontade, como uma espécie de gratidão à ideologia já cedida pela empresa, ideologia esta que acaba por direcionar também seus projetos pessoais. Tal projeto transforma o desejo do trabalhador em criatividade que deve ser mobilizada a serviço da companhia. Essa violência hipermoderna não é repressiva, 
ainda que subsistam formas de repressão. Diferente do modelo hierarquizado, o novo modelo gerencialista evoca a dimensão narcísica do trabalhador. Cabe ao trabalhador satisfazer seus desejos de onipotência, à custa de uma adesão total e mobilização política intensa.

Ainda se soma ao objetivo do artigo, a intenção de discutirmos que, em sendo uma prática institucional/ organizacional bastante comum no meio corporativo, a violência simbólica institucionalizada atua na construção de uma nova ética de "gestão de pessoas", que reifica as relações interpessoais no trabalho, valorizando apenas aqueles que, de alguma forma, contribuem no ganho financeiro da corporação (tal lógica vale para o cliente, empregados, colaboradores, gestores, fornecedores-parceiros).

\section{Sobre a história da violência simbólica}

Remontando à história, Althusser (1987) diferencia os aparelhos repressivos do Estado (que se utilizariam da violência para controle) das instituições consideradas "aparelhos ideológicos do estado", que se utilizariam de ideologia para controlar e garantir o funcionamento normal do sistema social. Depois de ter estudado o modo como se estrutura e funciona o aparelho ideológico do Estado escolar, Althusser desenvolve uma longa argumentação acerca da necessidade de formulação de uma teoria da ideologia em geral. Esse autor pode ser considerado um precursor da problematização da violência simbólica, juntamente com Bourdieu, pois pela primeira vez, assume-se a intencionalidade de se garantir a obediência através da educação formal.

As organizações comparadas a fábricas teorizadas por autores como Baudelot e Establet, (1971) Goffmann (1987) e Althusser(1987) chamaram de instituição total, legitimada pela sociedade e com funções específicas. Preparados pela escola, os trabalhadores, segundo Foucault (1975), teriam sido treinados e disciplinados nos movimentos milimetricamente controlados pelas instituições. Isso visando conseguir um comportamento de obediência e servidão, para que o trabalhador não venha a questionar a ordem social, assim como as relações já determinadas pela hierarquia social, econômica, que refletem o status quo. 
Para atingir a sua função social, as organizações/ instituições fazem uso do poder que lhe é delegado, ora para disciplinar os corpos, ora para homogeneizar os modos de agir dos seus internos, ora para mantêlos dentro de uma certa "normalidade", mais fácil de controlar. O disciplinamento dos corpos, denunciados pelos referidos autores, passa, na fase moderna e pós moderna, a incidir num plano mais subjetivo e menos físico. Com isso, vemos se estabelecer um modo de controle cada vez menor sobre os corpos, simbolizado pela vigilância presente, e o poder cada vez mais infiltrado na subjetividade do trabalhador, a ponto deste se confundir com o seu próprio controlador. A interiorização do controle e da sensação de constante vigília de si e de outros, deixa o trabalhador num estado de stress intermitente, além de se sentir num controle ilimitado. Em nível de América Latina, há publicações retratando a violência institucionalizada (COIMBRA, 1995; 2001; D'AUBETERRE ALVARADO, 2009), principalmente no Regime Militar, momento em que o discurso político se travestia de moralismo contra a ideologia "comunista" para garantir a manutenção da ordem sem ferir a moral militarista.

Foucault (1976), particularmente entre 1974 e 1976, abordou a judicialização da sociedade recolocando diversas controvérsias referentes à questão da vida em relação ao direito e às instituições políticas. Polêmicas que se cristalizaram em torno das noções de segurança e periculosidade, discurso que para Foucault, é revelador de uma profunda mudança na sociedade e no modo de governo dos indivíduos. Tal discussão se mostra bastante atual, principalmente no que se refere ao nosso debate aqui trazido. O que esse discurso difere em relação à época de Foucault é a busca pela polícia individual, em que se buscam algozes, vítimas e crimes entre pessoas físicas, numa corrida louca pela culpabilização e moção de processos jurídicos que alimentam o comércio do Direito.

Nesse contexto, a demanda por mais leis, normas, vigilância e punição não para de crescer; constitui parte intrínseca da produção e acumulação de capital e principalmente do chamado capital humano e do poder que com ele se instala e prolifera. No que concerne às relações laborais, podemos perceber que, apesar de esse fenômeno mover processos vultosos contra grandes corporações, o princípio seguido é o privado. A ação "violenta" é vista como um "deslize" ou erro de uma pessoa dentro da organização, que deverá pagar o "prejuízo" moral com uma significativa quantia em dinheiro. Essa é a 
prática de toda uma política generalizada do ódio às diferenças que faz também da inflação legalista e punitiva um negócio de primeira ordem; e que tem como motor principal enriquecer e se empoderar às custas de rebaixamento e submissão, capturando as forças intensivas dos modos mais interessantes de existência (FUGANTI, 2011; BERT, 2011).

Apesar de já termos superado modelos de trabalho que desconsideravam a inteligência do funcionário, encarando-o como máquina, como os modelos Taylorista e Fordista, e termos ingressados numa nova ordem de relações organizacionais mais horizontalizadas que valorizam a participação e a criatividade do funcionário (Toyotismo), ainda é notável a exploração desigual da empresa em relação ao funcionário em nome da ética do capital (RIBEIRO, 2009).

\section{A violência psicológica no mundo pós-moderno: o assédio pela performance}

O mundo pós-moderno rompe com paradigmas e parâmetros estáveis da organização do mundo moderno, inserindo valores como o risco, a flexibilidade, a ilegibilidade, deixando o trabalhador à deriva da possibilidade de planejar sua carreira profissional a médio ou longo prazo (SENNET, 1999). Com isso, deparamo-nos com um trabalhador que tem a sua rotina e valores (caráter) desvirtuados por uma lógica que prioriza a subserviência às mudanças instantâneas do mercado. Sennet (2000) propõe um entendimento de que o caráter do trabalhador pós moderno está corroído, tamanha é a instabilidade e a dificuldade de se manter os laços e compromissos entre trabalhadores e destes com a chefia.

Frente a esse cenário, surge um novo paradigma, que elegemos como nosso problema de pesquisa, que instiga os trabalhadores e grandes empresários a cultuar a sua autoperformance (EHRENBERG, 2010). Os trabalhadores não se mantem mais nas suas atividades pela sua experiência, conhecimentos, boas relações de lealdade com a corporação, mas assim, como num jogo esportivo, aquele que mostra maior competitividade se adequa melhor ao perfil esperado pelas empresas. $\mathrm{O}$ trabalhador que demonstra alta performance em relação às metas estipuladas é o que está no top dos mais requisitados pela corporação, até o momento em que a sua produtividade sofra uma 
queda. A figura do workaholic, outrora vista como uma patologia, hoje é considerada o ideal de dedicação no trabalho. O mundo do trabalho pós moderno assimila o discurso do competidor esportista: por se tratar de um jogo, ainda que as metas não tenham sido alcançadas naquela ocasião, há novas oportunidades de se recuperá-la, em outras partidas. Dessa forma, controla-se o sujeito de forma onipresente, como já havia teorizado Delleuze (1992), em sua sociedade do controle. Invadido por essa lógica que os controla todo o tempo, o trabalhador pode refletir para além do cotidiano de trabalho? Há formas de se escapar dessa onipresente ética do capital e da produtividade? Nosso projeto defende que sim, a partir de teorias que pregam o decrescimento econômico.

A cobrança pelo produtivismo corporativo torna o trabalho burocratizado e muito baseado em metas, o que, ocasiona uma sensação de intensa violência simbólica direcionada ao trabalhador, já que inviabiliza a sua autonomia, tornando-o mero executor de objetivos mercadológicos e financeiros definidos a priori pelas corporações. Em nosso ponto de vista, quando o valor do trabalho se mede meramente a partir da produtividade (metas, ganhos, prejuízos, desemprego), desconsiderando a experiência, o saber do funcionário, seu relacionamento com os demais da equipe e as condições em que as vendas ocorrem, e o sentido do trabalho se perde por completo. Podemos problematizar quais seriam as consequências de uma lógica que é tão contraditória? No capitalismo, a exaltação do consumismo e das falsas necessidades do cliente consomem o trabalhador na sua atividade, preenchendo o tempo de trabalho com atividades que não fazem sentido àquele que as desempenha. Não faz sentido, pois atua-se sobre necessidades falsas, produzidas, muitas vezes, às custas do uso de estratégias não éticas para se fechar um bom negócio. (GAULEJAC, 2007; SENNETT; 2001) A contradição nesse trabalho não para por aí: faz com que o trabalhador seja premiado individualmente pela sua produtividade, sendo que tais desempenhos dependem do conjunto de trabalhadores. (GAULEJAC, 2007) Desperta no trabalhador um sentimento de onipotência, fazendo-o pensar ser sempre possível atingir ou superar as metas. Ao mesmo tempo, o controle e a vigília se dão não só física, mas, principalmente, atuando na subjetividade, dando-nos uma sensação de impotência em questionar tal ordem. Enquanto se exige do trabalhador uma postura proativa e original, esse mesmo sistema cerceia sua autonomia através de um controle quase infinito. Podemos questionar: mas, então, que autonomia é essa? 
Em que pese todas essas questões, a submissão do trabalhador às diretrizes da empresa é livremente consentida, uma vez que o controle se dá de forma tão eficaz e reticular que somos nossos próprios fiscais. Queremos trabalhar pois precisamos pagar nossas contas, ao mesmo tempo em que somos levados (ou assediados) a cometer ações que vão contra nossos posicionamentos, em troca de se permanecer na empresa por um tempo a mais. Frente à flexibilidade característica do meio corporativo, nem a garantia da permanência na corporação temos mais, já que ela fica à deriva dos fluxos inconstantes do mercado. (SENNET, 2001). O querer do funcionário faz com que ele mesmo se cobre por produtividade, interiorizando de modo consentido as diretrizes corporativas. Nesse sentido, como poderíamos controlar o assédio, se ele não ocorre apenas de fora pra dentro?

Autores como Sennet (2001) e Gaulejac (2007) denunciam que a ética pelos resultados impõe uma cobrança ao trabalhador em que os "fins" justificariam os "meios": para se atingir as metas, quaisquer que sejam os instrumentos usados pelos trabalhadores são aceitáveis. Dejours (2005) analisa a alta incidência de tais práticas imorais na pósmodernidade como a banalização da injustiça social. Esse aumento se dá por conta de uma tolerância maior a uma ética subjugada a valores mercantis e financeiros, o que torna as relações humanas e em grupo insignificantes e baseada em laços frágeis e pragmáticos, intolerantes às falhas e afetações humanas. A exigência por uma performance de máquina e uma produtividade focada em metas muito além do que é possível um trabalhador produzir nos mostra que o sistema racional capitalístico financeiro é intolerante às características humanas dos trabalhadores que executam tais atividades. Nesse sentido, acompanhamos a medicalização dos trabalhadores, que se utilizam principalmente de psicotrópicos como formas de adaptação à rotina flexível e à incessante cobrança que as corporações instituem sobre seus funcionários. $\mathrm{O}$ uso disseminado de medicamentos para ora aumentar a produtividade, ora permitir o descanso, ora diminuir a ansiedade e a solidão trata-se de um processo complexo que infelizmente encara a falta de produtividade do trabalhador como uma doença orgânica que, ao ser medicada, adapta o trabalhador à demanda e encerra um debate macrossistêmico. Certamente a nova ontologia do trabalhador pós moderno: performático, individualista e lucrativo, assim como as falhas desse sujeito não são possíveis de serem "curados" com a ingestão de psicofármacos que garantam a performance e a produtividade do trabalhador. Fazer uso do 
medicamento para solucionar uma questão sociológica, econômica e cultural da pós-modernidade pode ser mais um sintoma da intolerância e da imediaticidade social. Esses novos valores falam de uma ontologia do sujeito que perpassa interesses financeiros e de produção, mas que deixam à deriva as demandas subjetivas do trabalhador, que continua ansioso, angustiado e se sentindo só.

Daí os autores concluírem que estejamos passando por uma crise na ética corporativa. Com o caráter corroído, gestão e trabalhadores ficam mais suscetíveis a ações antiéticas que, consequentemente, se traduzirão em atitudes "assediosas".

\section{Considerações finais:}

Concluindo, gostaríamos de voltar à etimologia da palavra assédio, que, em latim olesidere, (HOUAISS, 2001) significa pôr-se adiante, sitiar atacar. O questionamento que faço é: na atual visão de gestão que incentiva funcionários a usarem táticas de guerra para conseguir resultados, não seria totalmente tolerável ou banalizado usarmos estratégias agressivas e sem limites de ataque? O que eu quero dizer é que numa sociedade de indivíduos sob pressão, a prática do assédio é bem coerente com uma postura proativa e agressiva para se atingir o objetivo a que todo trabalho pós moderno se submete: cumprimento das metas e otimização da produção.

A violência simbólica, pois, não se trata de um ato errado individual do gestor ou do funcionário que assedia. Mais do que isso, trata-se de um comportamento bastante incentivado nos mais diferentes âmbitos, mas principalmente no corporativo, pois ali, impera com mais força a lógica do lucro a todo preço. As práticas das empresas desenvolvem as convicções e valores nos quais os empregados devem se comprometer a crer. Eles se empenham em compensar a lógica do lucro por meio de construções morais, destinadas a legitimá-las. Todo esse processo se dá de modo a capturar ideologicamente o trabalhador, minimizando seu senso crítico em relação às contradições típicas do modo de produção capitalista (PAGÉS et al, 2001).

Frente a esse processo, o indivíduo se encontra abandonado a si mesmo. Por isso chamamos esse processo de privatização de 
fenômenos marcadamente globais e referentes à configuração social, onde podemos perceber planetariamente uma tendência à desfiliação social do indivíduo frente à, antes existente, seguridade social ou o Estado de Proteção Social (CASTEL, 2005). Em busca da gestão de si mesmo, a infinitude das cobranças, metas e necessidade de querer sempre ser o primeiro em busca do sucesso quebra o rigor ético necessário para a manutenção do relacionamento interpessoal.

É nesse contexto que surge o que chamamos aqui de violência simbólica institucionalizada nas corporações. Numa sociedade capitalizada, mercantilizam-se os direitos, as reivindicações, privatizando discussões que deveriam se dar em espaço público, à diversidade de opiniões, à vontade geral. Certamente, a ética nas relações laborais trata-se de um tema que deve ser levado a público para se debater com trabalhadores, especialistas, gestores de corporações, governo. Ao invés disso, o que temos presenciado tem sido a corrida pelo mercado da judicialização dos direitos, que interessa apenas à cadeira comercial que este negócio gera.

Toda essa discussão aqui tratada imprime novos desafios ao exercício do direito do trabalhador. É necessário um debate politizado e aberto a novas ideias sobre questões tais como processos de formação, trabalho e saúde dos trabalhadores, financiamento da seguridade social, modos de gestão das corporações, dentre outras questões. Tais tensionamentos como analisadores das artes de governar têm tecido os processos de formação e gestão, entendendo que o contemporâneo nos convoca à análise dos novos perigos e a produção de exercícios éticos. O sucateamento da vida vai sendo gestado com políticas que produzem relações de trabalho piedosas, aplacando os desassossegos e tensionamentos com medicalizações, judicialização da vida e culpabilizações. Essas políticas gerem a vida rechaçando suas variações e estabelecem um corte entre os que devem viver e os que deixaremos morrer, tecendo processos de formação para governar a vida, mantendo a ordem necessária. Para todas essas ações, os dispositivos de segurança estatais são acionados.

Alguns questionamentos se fazem necessários: $O$ que poderia constituir uma autêntica reação a esse estado de coisas e demanda por justiça no trabalho? Como produzi-la de forma criativa, coletiva e disruptiva? Como ativar possibilidade de socialização entre os trabalhadores, de modo a se reconstruir debates que trazem à tona a 
discussão sobre o controle sobre o trabalhador? Como driblar o controle de si por si mesmo?

\section{Referências:}

ALTHUSSER, L. Aparelhos Ideológicos de Estado. Rio de Janeiro: Graal, 1987.

BAUDELOT, C. \& ESTABLET, R. L'École capitaliste en France. Paris: Librairie François Maspero, 1971.

BERT, J.F. Segurança, periculosidade, biopolítica: três abordagens de uma nova prática de poder sobre os indivíduos. In: I Colóquio internacional Michel Foucault: A judicialização da vida. Rio de Janeiro: UERJ, 2011.

BOURDIEU, P. La reproduction. Paris: Ed. de Minuit, 1970.

CASTEL, Robert. As metamorfoses da questão social: uma crônica do salário. Tradução de Iraci D. Poleti. Petrópolis: Vozes, 1998

COIMBRA, C. M. B. Guardiões da Ordem: uma viagem pelas práticas psi no Brasil do 'milagre'. Rio de Janeiro: Oficina do Autor, 1995.

. Operação Rio: o mito das classes perigosas. Rio de Janeiro: Oficina do Autor/Intertexto, 2001.

D'AUBETERRE ALVARADO, Luis Alberto. Violencia social y discurso político presidencial Venezolano: un estudio psicosocial. Psicol. Soc., Florianópolis , v. 21, n. 3, Dec. 2009

Dicionário Houaiss da Língua Portuguesa. Rio de. Janeiro, Ed. Objetiva, 2001.

EHRENBERG, A. O culto da performance: da aventura empreendedora à depressão nervosa. São Paulo: Ideias e Letras, 2010.

FOUCAULT, M. Vontade de Saber. Rio de Janeiro: 1976. 
FUGANTI, L. (2011)A judicialização como forma da governamentalidade contemporânea confiscar, controlar, capitalizar e gerir as forças intensivas do homem. In: I Colóquio internacional Michel Foucault: A judicialização da vida. Rio de Janeiro: UERJ, 2011.

GAULEJAC, Vincent de. Gestão como doença social: ideologia, poder gerencialista e fragmentação social. Aparecida, SP: Ideias \& Letras, 2007.

GOFFMAN, E. Manicômios, prisões e conventos. São Paulo: Perspectiva, 1987.

HECKERT, A.L; ROCHA, M.L. A maquinaria escolar e os processos de regulamentação Da vida: embates e aprisionamentos. In: I Colóquio internacional Michel Foucault: A judicialização da vida. Rio de Janeiro: UERJ, 2011.

PAGÉS, Max et alli. O poder das organizações. São Paulo: Atlas, 1993

SENNETT, R. O declínio do homem público: as tiranias da intimidade. São Paulo: Companhia das Letras, 1999.

A corrosão do caráter. São Paulo: Record, 2001. 